\title{
บUsisersily
}

\section{A simple modelling tool for assessing interaction with host and local infestation of sea lice from salmonid farms on wild salmonids based on processes operating at multiple scales in space and time.}

Murray, A. G., \& Moriarty, M. (2021). A simple modelling tool for assessing interaction with host and local

infestation of sea lice from salmonid farms on wild salmonids based on processes operating at multiple scales in space and time. Ecological Modelling, 443, [109459]. https://doi.org/10.1016/j.ecolmodel.2021.109459

Link to publication record in Ulster University Research Portal

Published in:

Ecological Modelling

Publication Status:

Published (in print/issue): 01/03/2021

DOI:

https://doi.org/10.1016/j.ecolmodel.2021.109459

\section{Document Version}

Author Accepted version

\section{General rights}

Copyright for the publications made accessible via Ulster University's Research Portal is retained by the author(s) and / or other copyright owners and it is a condition of accessing these publications that users recognise and abide by the legal requirements associated with these rights.

\section{Take down policy}

The Research Portal is Ulster University's institutional repository that provides access to Ulster's research outputs. Every effort has been made to ensure that content in the Research Portal does not infringe any person's rights, or applicable UK laws. If you discover content in the Research Portal that you believe breaches copyright or violates any law, please contact pure-support@ulster.ac.uk. 
2 A simple modelling tool for assessing interaction with host and local infestation of sea lice from 3 salmonid farms on wild salmonids based on processes operating at multiple scales in space and 4 time

Alexander G Murray and Meadhbh Moriarty

Sandy.Murray@gov.scot

Marine Scotland Science, Marine Laboratory

375 Victoria Road, Aberdeen AB11 9PE, UK

Key Words: salmon, aquaculture, sea lice, infestation, kernel model, plume, infection pressure

\section{Abstract}

Sea lice are marine ectoparasitic crustacea which limit the potential for sustainable salmon aquaculture due to risks of impacts on iconic wild salmon and sea trout. Control of the parasite on farms costs an estimated $9 \%$ of farm revenue. Sea lice develop through planktonic nauplii to copepodid stages which attach to, and mature on, salmonid hosts until females become ovigerous (egg laying) Impacts of lice on wild fish depend on their exposure to planktonic larval lice transported from salmon farms, which consists of $(A)$ production of larval lice from ovigerous female lice on salmon farms, (B) local concentrations of planktonic larval lice infectious copepodids in adjacent waters, (C) rates of infestation of wild fish given these concentrations, and (D) impact on fish given this level of interaction. A model of this local exposure around salmon farms was developed. Production rates for nauplii as a function of the numbers of adult lice on salmon farms and maturation to copepodids (A) is well studied, as are impacts of infestation (D), with $>0.75$ lice per gram of host fish considered to present a high risk of mortality. Using existing assessments of infectious copepodid production (A) we develop a model of copepodid concentration (B) based on a simple kernel of copepodid distribution around farms; within this kernel the copepodids are assumed either to disperse evenly or to be transported in a concentrated plume, allowing comparison of the range of different concentration distributions. These distributions combine with a model of infestation (C) based on small-scale movements of copepodids in the immediate vicinity of a swimming fish. Fish swimming at intermediate velocities are most susceptible to infestation, as slow fish exhaust lice in their immediate vicinity while fast fish move on before lice copepodids can approach. These models are combined to create an assessment of the risk that concentrations can result in infestation of fish at levels considered to cause mortalities (D). The results can be used in combination with empirical assessments as a tool to link potential impacts on wild salmonids to aquaculture biomass and on-farm lice management in different environments in support of strategic aquaculture planning. Our modelling demonstrates the, often neglected, importance of fine-scale processes in sea lice infestation of salmonids.

\section{Introduction} (Pradeepkiran 2019) with a relatively low carbon footprint (Zeigler et al. 2013) although airfreighting 
can undermine this. Annual global salmon production has expanded to 2.25 million tonnes and much is produced in relatively remote areas. Production is distributed $55 \%$ in Norway, $25 \%$ Chile, $7 \%$ Scotland, 6\% Canada, 3\% in the Faeroe Islands with several smaller production countries (Iversen et al. 2020). Salmon aquaculture is an important contributor to the economy of salmon producing countries and particularly the relatively remote regions within these countries where production occurs.

The salmon industry strives to become more sustainable and environmentally responsible, through codes of good practice, combined with legislation and official inspections. Production of sustainable salmon requires a number of important issues to be addressed with the best available scientific information underlying key decisions. These issues include, risks to wild fish from parasites (Taranger et al 2015). A key factor limiting aquaculture expansion, is the local density of the salmon louse, Lepeophtheirus salmonis, whose impact is critical to the sustainability of aquaculture (Sandvik et al. 2020). L. salmonis is a major problem in most northern hemisphere marine production (Jones and Beamish 2011), and in Chile the louse Caligus rodgercressyi causes similar problems (Mancilla-Schulz et al. 2019). Lice present a major problem to farming of salmon as their control is expensive, costing about $9 \%$ of farm revenues (Abolfia et al. 2017) and they can cause welfare and other problems.

Although adult lice are attached to and feed on salmon within farms, they also have more widespread effects because they produce juvenile stages, termed nauplii and copepodids, that disperse beyond farm boundaries in water currents and the latter stage are infectious (Hamre et al. 2013). Sea lice can reduce wild populations of both Atlantic salmon and sea trout if not controlled on farms (Vollset et al. 2016, Serra-Llinares et al. 2020). Lice production from large host populations on farms (Heuch and Mo 2001) can expose wild fish to high concentrations independent of lice production on that wild population (Murray 2009). Exposure to lower concentrations over prolonged periods can also create risks. It is this risk to wild fish, rather than the impacts on farmed fish, that is the key limitation on acceptable sea lice levels on farms (Taranger et al. 2015).

If salmon aquaculture is to be expanded sustainably then it is necessary to identify areas where sea lice may have an unacceptable impact on wild salmonids. To make this assessment requires estimation of the production of sea lice from aquaculture, their dispersal and distribution in the environment over time, and the impact the resultant concentrations may be expected to have on salmonids. Although complex hydrodynamics and biology are involved, simple robust modelling tools can capture essential features and act as a potential planning tool. Area management tools are applied in all countries with salmon aquaculture (Murray and Gubbins 2016).

In this paper we derive a simple modelling approach to describe distribution of sea lice and its relationship with salmon farms at the local level to help support planning. This is intended to assist assessment of potential for impacts of a farm on neighbouring wild salmonid populations. To do this we seek to create a simple modelling tool, while acknowledging complexities such as the interactions of multiple farms and areas (Adams et al. 2016) and seasonality in distances over which interaction occurs (Samsing et al. 2017) that are described in the discussion section of this paper.

\section{Methods}

The modelling analysis of risk to wild salmonids depends on four factors, $(A)$ the numbers of nauplii produced from lice on a farm and maturation to become infectious copepodids, (B) the spatial distribution of the resultant infectious copepodids by area, $(C)$ the resultant risk to fish of infection when exposed to these concentrations and (D) impact of the level of infection (Fig.1). 


\begin{tabular}{|c|c|c|c|}
\hline $\begin{array}{l}\text { (A) Lice } \\
\text { production } \\
\text { from farm }\end{array}$ & $\begin{array}{l}\text { (B) Copepodid } \\
\text { distribution = } \\
\text { infection } \\
\text { pressure }\end{array}$ & $\begin{array}{l}\text { (C) Exposure } \\
\text { of host fish = } \\
\text { infection }\end{array}$ & $\begin{array}{c}\text { (D) Lice } \\
\text { impact on host }\end{array}$ \\
\hline
\end{tabular}

Figure 1. Stages in identification of local risk to wild salmonids

\section{A. Lice production}

Larval lice production depends on the rate of egg production from each ovigerous female, the survival of offspring through two dispersing nauplii phases to become infectious copepodids and their period of survival during which these copepodids can infect fish (Hamre et al. 2013). It is only the copepodids that contribute to infection pressure and hence the risk generated by sea lice from a farm. This process gives copepodid production per ovigerous female, which is multiplied by these lice on the farm (ovigerous female lice per fish $\times$ number of fish on the farm) to generate $\mathrm{N}$, the number of copepodids the farm would cause to be present in the environment at any one time.

Table 1. Model variables and parameters for risk of infection due to copepodid distribution

\begin{tabular}{|c|c|c|}
\hline Name & Description & Unit \\
\hline $\mathrm{T}$ & Total number of infectious copepods in kernel around a farm & Lice \\
\hline $\mathrm{N}_{\mathrm{x}}$ & Number of copepodids reaching $\mathrm{x} \mathrm{km}$ from source & Lice \\
\hline$C_{x}$ & Concentration of copepodid at distance $x$ & Lice $\mathrm{m}^{-2}$ \\
\hline $\mathrm{C}_{\mathrm{T}}$ & Threshold concentration causing unacceptable load per fish & Lice $\mathrm{m}^{-2}$ \\
\hline $\mathrm{x}$ & Distance from source & $\mathrm{km}$ \\
\hline $\mathrm{x}_{\max }$ & Fitted maximum distance in decay curve & $\mathrm{km}$ \\
\hline$\alpha$ & Fitted decay parameter with distance & \\
\hline Z & Depth over which most copepodids are present & $\mathrm{m}$ \\
\hline $\mathrm{D}$ & Time in days & d \\
\hline$V_{f}$ & Volume of fish & $\mathrm{cm}^{3}$ \\
\hline$I_{f}$ & Length of fish & $\mathrm{cm}$ \\
\hline$r_{f}$ & Radius of fish & $\mathrm{cm}$ \\
\hline$\lambda_{\mathrm{s}}$ & Copepodid velocity & $\mathrm{cm}$ \\
\hline $\mathrm{X}$ & Distance over which copepodid approach a moving host & $\mathrm{cm}$ \\
\hline$\tau_{\max }$ & Time from stimulation over which lice move towards a stationary host & $\mathrm{s}$ \\
\hline B & Speed of fish in body-lengths per second & $\mathrm{s}^{-1}$ \\
\hline$U_{w}$ & Volume of water from which copepodids contact a moving fish & $\mathrm{cm}^{3} \mathrm{~s}^{-1}$ \\
\hline $\mathrm{a}$ & Probability of attachment on contact & \\
\hline K & Rate at which copepodids contact the host & Lice $\mathrm{s}^{-1}$ \\
\hline $\mathrm{Y}$ & Maximum lice load per gram of host & Lice $\mathrm{g}^{-1}$ \\
\hline G & Rate per $\mathrm{km}$ travelled that fish pick up lice & Lice $\mathrm{km}^{\mathrm{H}}$ \\
\hline $\mathrm{H}_{\mathrm{t}}$ & Distance fish must travel to pick up lice above threshold level & $\mathrm{km}$ \\
\hline
\end{tabular}


Lice interact with their hosts through processes operating at different scales in space and time (Murray and Salama 2018). Movements of lice copepodids and lengths of fish are generally considered at scales of centimetres and seconds, concentrations of copepodids over areas are considered per square metres, and long-distance transport of copepodids and movement of fish are generally reported in kilometres and days. We apply the most appropriate units for each process to generate results that can be compared with literature reports, but this does require conversion factors to be included in some equations.

We take existing modelling and parameterisation to generate production of copepodids. Although egg string length varies with environment, including temperature, louse age and between wild and famed fish (Stien et al. 2005, Brooker et al. 2018), here, in line with existing model practice, we assume ovigerous females produce two egg strings of 150 eggs each, these are replaced approximately every ten days (e.g. Skarđhamar et al. 2018). This gives the egg production generated per louse of 30 eggs per day.

Lice mature through two nauplii phases before they become infectious as copepodids (Hamre et al. 2013), the time for this process approximates to 40 degree days, hence for example at $10^{\circ} \mathrm{C}$ this is 4 days. During this period the larvae are transported through the environment and may die, for simplicity a standard mortality rate of $1 \%$ per hour is typically used (Amundrud and Murray 2009). With this parameterisation, at $10^{\circ} \mathrm{C}, 38 \%$ of hatched eggs reach the infectious copepodid phase.

Survival period can vary with temperature (Brooker et al. 2018), we assume the mature copepodids can survive for up to 10 days before they run out of energy and starve. The sum of surviving copepodids over 10 days is $\Sigma\left(0.99^{24^{*} \mathrm{D}}\right)$, where $D=\{0, \ldots, 10 \mathrm{~d}\}$. This sum gives 4.2 copepodid days for each copepodid that matures from the nauplii phases, i.e. the mean copepodid survives 4.2 days. Nauplii and copepodids do not feed, so after energy reserves are exhausted the copepodid dies if it has not infected a host, this gives a fixed maximum length of survival rather than adding to decay rate. Effects on infection pressure of differences in time to starvation are relatively small, for example if lice are assumed to survive an extra $20 \%$ to 12 days the mean survival time increases only $3.8 \%$ to 4.4 days.

Therefore at $10^{\circ} \mathrm{C}$ the infection pressure, which is the average number of surviving copepodid lice produced per adult female lice $=30 \mathrm{If}^{-1} \mathrm{~d}^{-1} \times 0.38 \times 4.2 \mathrm{~d}=47.88$ copepodid per fish (30 eggs per day, with $38 \%$ survival to copepodid and 4.2 mean days copepodid survival). This multiplied by the number of fish on a farm multiplied by the number of lice per fish, gives the lice being released into the environment (Table 2). Under changing temperatures parameters will change (Stien et al. 2005).

The number of fish that a farm may contain can be estimated from the maximum biomass consented by authorities and an estimate of average fish size when harvested. Given an average weight of $5 \mathrm{~kg}$ for a harvestable fish, a farm with 1000 tonne consent would contain between 200,000 and 300,000 fish. Numbers of fish on the farm may be higher earlier in the cycle owing to mortality and ongoing harvesting, however highest lice numbers per fish are typically found later in the production cycle (Revie et al. 2002). So it is reasonable to assume larger size fish are most likely to be associated with high ovigerous lice loads, thus we assume only 200,000 fish is appropriate for our analysis for a 1000 tonne consented biomass. 
Table 2. Copepodid, C, production from farms per 1000 tonnes consented. Parameter units: I = lice (any development stage), $d=$ days, $f=$ number of fish on farm, $h=$ hour. Total column describes calculation of lice production stage by stage to calculate $\mathrm{N}$ dependent on farm size.

\begin{tabular}{|l|l|l|}
\hline Factor & Rate & Total \\
\hline $\begin{array}{l}\text { Egg production per } \\
\text { ovigerous louse }\end{array}$ & $30 \mathrm{I} \mathrm{d}^{-1} \mathrm{f}^{-1}$ & $30 \mathrm{I} \mathrm{d}^{-1} \mathrm{f}^{-1}$ \\
\hline Mortality rate & $1 \% \mathrm{~h}^{-1}$ & \\
\hline Survival to maturation & 0.38 & $11.4 \mathrm{Id}^{-1} \mathrm{f}^{-1}$ \\
\hline $\begin{array}{l}\text { Copepodid maximum } \\
\text { survival }\end{array}$ & $10 \mathrm{~d}$ & $47.88 \mathrm{If} \mathrm{f}^{-1}$ \\
\hline $\begin{array}{l}\text { Copepodid average } \\
\text { survival days }\end{array}$ & $4.2 \mathrm{~d}$ & $9.576 \times 10^{6} \mathrm{I}$ \\
\hline $\begin{array}{l}5 \text { kg fish per 1000 } \\
\text { tonne farm }\end{array}$ & $200,000 \mathrm{f}$ & $\mathrm{N}=2 \times 10^{7} \mathrm{I}$ \\
\hline $\begin{array}{l}\text { Ovigerous lice per fish } \\
\text { reporting threshold }\end{array}$ & 2 & $\mathrm{~N}=6 \times 10^{7} \mathrm{I}$ \\
\hline $\begin{array}{l}\text { Ovigerous lice per fish } \\
\text { enforcement } \\
\text { threshold }\end{array}$ & 6 & \\
\hline
\end{tabular}

If we assume an average of one ovigerous louse per fish on a given farm with 200,000 fish, and each fish results in 47.88 copepodid days per day, this approximates to 10 million $\left(9.576 \times 10^{6}\right)$ copepodid being present in the environment at any one time. In Scotland, the number of lice per fish data are published monthly by the Scottish Salmon Producers Organisation (www.scottishsalmon.co.uk/reports), but for planning purposes the reporting threshold of 2 ovigerous lice per fish, over which farms undergo increased official surveillance, and the upper threshold of 6 ovigerous lice per fish at which enforcement action is taken determine ovigerous lice per fish limits (https://www2.gov.scot/resource/0051/00516518.pdf). Thus 20 to 60 million copepodids would be produced per fish per day from 1000 tonne farms operating at these limits. This means that $T=20$ to 60 million viable copepodids would be in the environment in the vicinity of the farm at any one time.

\section{B. Infectious copepodid distribution kernel}

Larval lice are transported by currents, so may cause infection pressure at locations away from the source when they mature into infectious copepodids. The nature of this dispersal depends on complex hydrodynamics and some larval lice are transported over long distance (Rabe et al. 2020). Infection pressure can be modelled, however, using simplified assumption of currents or kernels of concentration risk around farms (Cantrell et al. 2018), by simple advection dispersal based models (Krkošek et al. 2005), or taken from averaging patterns from more complex hydrodynamic models (Salama et al. 2016). Using these simple distribution patterns, the locations likely to be at risk from local infection sources can be derived. Thus, local impact of farms, including potential new farms, can be assessed to provide initial advice for suitable farm size in different locations. 
systems. This model allows impacts of different mixing depths to be specifically assessed, as mixing dilutes the concentrations per cubic meter.

Kernels of distribution concentration can be taken from strength of the interactions between sea lice populations on different farms (Aldrin et al. 2013, Kristoffersen et al. 2014), observed infestation of wild salmonids (Middlemas et al. 2013) or from average properties taken from more complex hydrodynamic models (Salama et al 2016). The latter option has been used to derive a kernel of probability of lice copepodids with distance from a source farm using the decay curve of:

$$
\mathrm{N}_{\mathrm{x}}=\mathrm{N}_{\mathrm{o}}\left(1-\mathrm{x} / \mathrm{x}_{\max }\right)^{\alpha}
$$

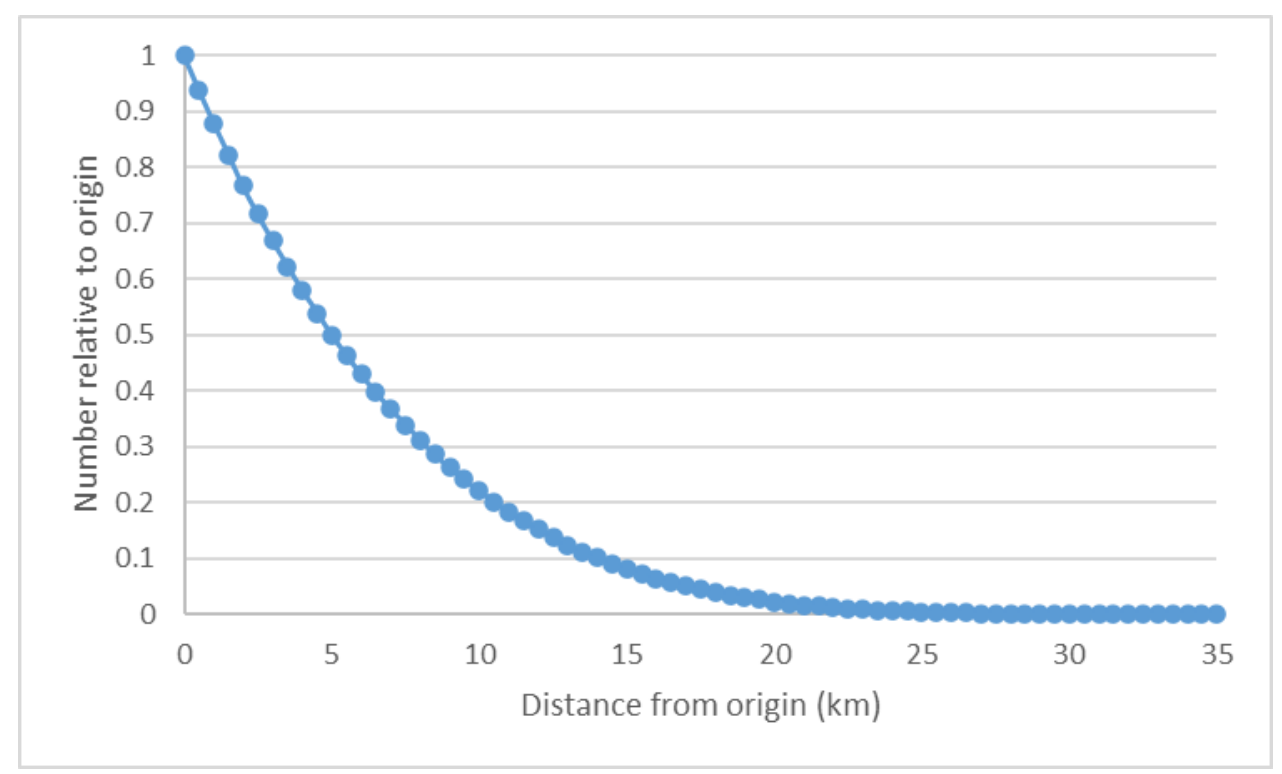

Figure 2. Kernel distribution proportion of copepodids retained within given distances from their source. The distribution curve is from Salama et al. (2016) averaging complex hydrodynamic model results from multiple sources.

The optimal value of $\alpha=4.5$ and $x_{\max }=35 \mathrm{~km}$, distance from source is denoted as $x$ (Salama et al. 2016). This curve means that $90 \%$ of lice of infection pressure is within $12.8 \mathrm{~km}$ of their origin (Fig. 2). For normalised distribution $N_{0}=1$, but this is evaluated dependent on the size of the farm and lice per fish.

The number of copepodids $N_{x}$ actually represents is the total number produced by the farm distributed over the curves. This is achieved by normalising the curve with $\mathrm{N}_{0}$ set so that the integral of $\mathrm{N}_{\mathrm{x}}=\mathrm{T}$,

$$
T=\int_{x=0}^{x=x_{\max }} N_{x}
$$

Copepodids can be distributed in numbers that reflect this decay curve; the decay curve is representative and concentrations will vary with local current patterns and can be improved by further hydrodynamic modelling. This number, is distributed over an increasing area with distance at concentration per square meter. At one extreme the particles could be distributed evenly over the increasing circle $\pi x^{2}$ (Fig. 3). The concentration of risk at a given distance $x, C_{x}$, is the number of 
copepodids divided by the area over which these particles are dispersed $C_{x}=\left(N_{x}-N_{x-\delta x}\right) /\left(\pi x^{2}-\pi(x-\right.$ $\left.\delta \mathrm{x})^{2}\right)$, where $\delta \mathrm{x}$ is a small distance tending to zero.

Note that concentration is defined per unit area, this standardises distribution of copepodids with distance from farm and is in line with lice assessment for management. However, to calculate the encounter rate we divide this by the depth (Z) over which lice are distributed.

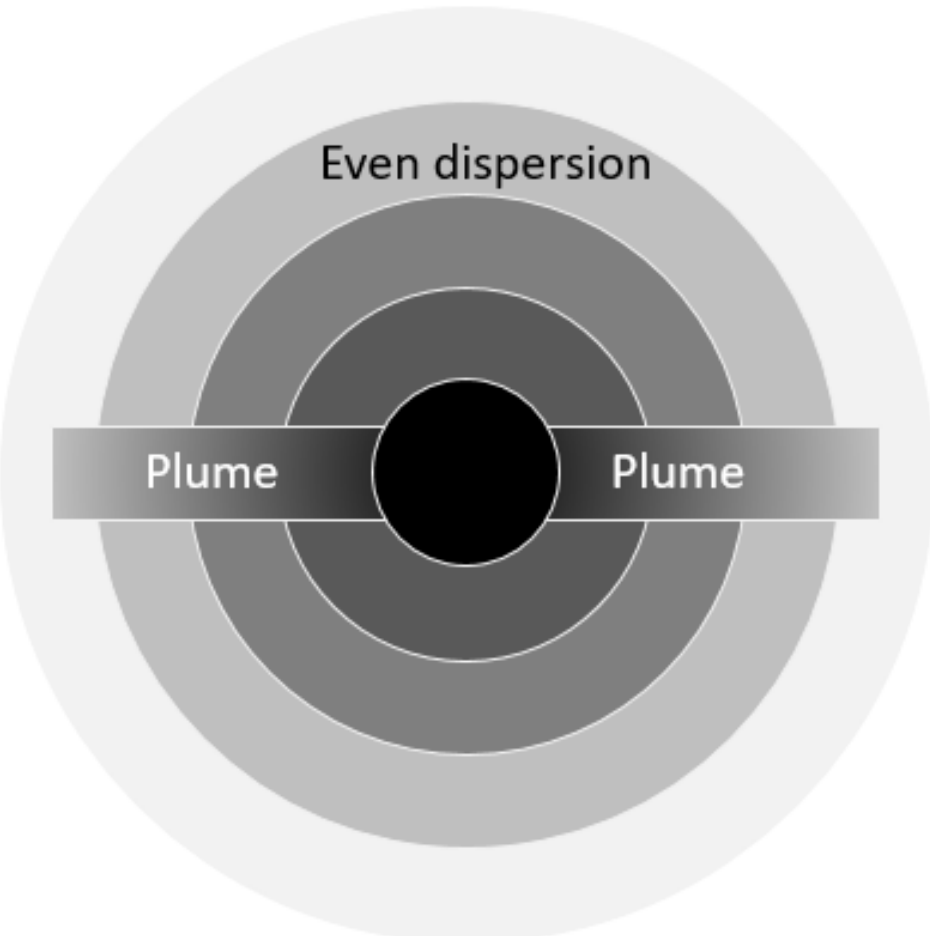

Figure 3. Conceptual diagram showing uniform dispersal dilutes concentration (increasing circles with paler grey shades) into larger and larger area with distance from source while plume covers same area (dark grey with slight gradient). This dilution distribution is multiplied by the numbers of lice in the kernel (distribution with distance shown in Fig. 2), so for uniform dispersal this means concentration becomes very low with larger distances from source.

At the other extreme particles may be transported as a plume (Fig. 3) that maintains a more or less constant width (Murray and Salama 2018). In this case we assume a narrow, nearly 1-D, tidally generated current with two plumes leaving the farm as the current can transport in alternately in both directions from the source. Under these assumptions the particles simply follow the decay curve divided by twice the plume width, $\mathrm{C}_{\mathrm{x}}=\left(\mathrm{N}_{\mathrm{x}}-\mathrm{N}_{\mathrm{x}-\delta \mathrm{x}}\right) / 2 \mathrm{w} \delta \mathrm{x}$. Concentration in a plume may remain relatively high with distance, however the greater the distance the lower the probability unidirectional currents will persist to carry the plume to that distance and so the lower the risk of infection. More geographically complex distributions can be generated by more realistic hydrodynamics (Salama et al. 2018), here we seek to use the kernels obtained from this model to generate simple but plausible copepodid concentrations that fish may encounter. 
To assess potential impact of concentrations of copepodids within the water column it is necessary to look at potential infestation rates on salmon smolts. Smolts are salmonids that are entering seawater for the first time at the end of their freshwater growth phase (Thorstad et al 2012). As smolts are the smallest salmonid fish in the sea they are the most likely to be exposed over a given time to levels of sea lice infestation that could cause severe problems or risk of death, since these negative effects are proportional to the number of lice per gram of host fish. However, smolts tend to migrate relatively quickly through coastal waters (Johnsen et al. in press), thereby limiting their exposure time.

Wild salmon smolts usually range in length from about $10-20 \mathrm{~cm}$ long and weigh from 10-80 g each (Thorstad et al. 2012, Malcom et al. 2015). This equates to $10-80 \mathrm{~cm}^{3}$, assuming fish density approximates to water and is directly occupied by the fish. However, the volume effectively occupied by the fish is larger because the lice can move towards the fish (Fig. 4). The volume within a distance from which copepodids can contact the host gives the volume of water from which the sea lice can contact the host, once the volume displaced by the host is removed.

The speed of a copepodid approaching its target, effectively increases the target size. Sea lice copepodids are able to sense their host and home in on it (Mordue (Luntz) and Birkett 2009). Swimming velocity of a sea louse is typically about $1.55 \mathrm{~mm} \mathrm{~s}^{-1}$, but increases to about $17 \mathrm{~mm} \mathrm{~s}^{-1}$ for 1-3 seconds on mechanical stimulus (Heuch and Karlsen 1997), with small numbers of copepodids swimming up to $9 \mathrm{~cm}$ in the first second; we consider speeds of up to $5 \mathrm{~cm} \mathrm{~s}^{-1}$ to describe the range velocity and its reaction time, but the time available is reduced dependent on the speed the fish moves past.

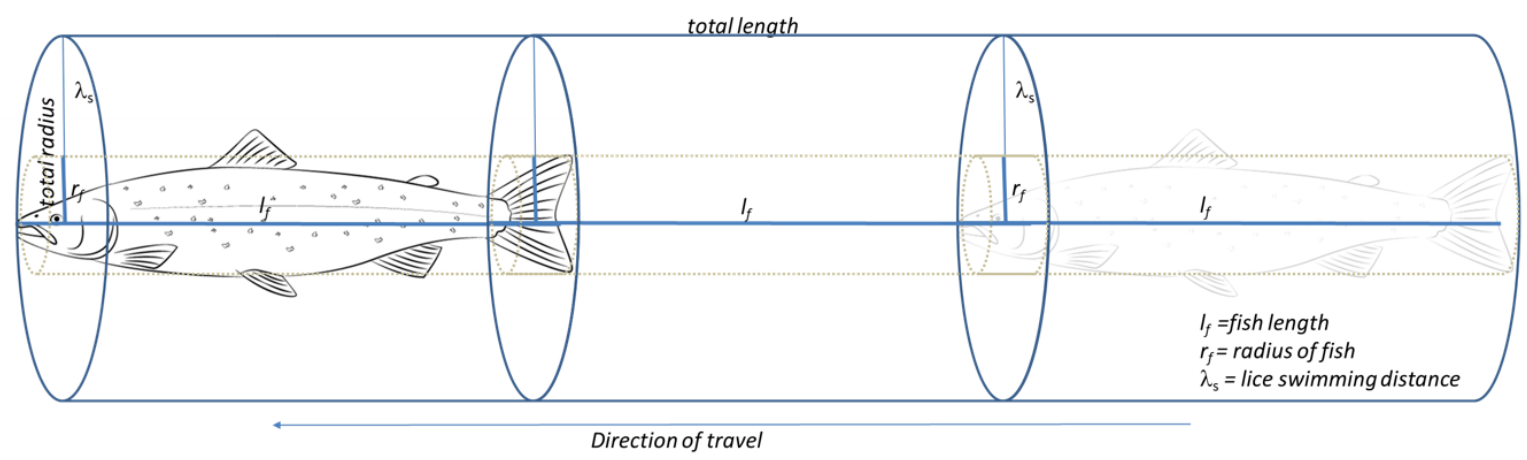

Figure 4: Conceptualization of the effective surface area for host encounters between salmonids and lice copepodids for a fish moving at three body lengths per second). The water volume and the fish, are treated as cylinders for simplicity.

For simplicity we treat fish as cylindrical with a volume

$$
V_{f}=\pi r_{f}^{2} \times I_{f}
$$



$=0.56 \mathrm{~cm}$, or $1.13 \mathrm{~cm}$ for a $20 \mathrm{~cm}$ smolt.

However fish are moving, typically at $1-3$ body-lengths per second, B, (Thorstad et al. 2012). The model uses a time step, that is, the time copepodids have to approach the fish. This is either the time copepodids react to stimulation, $\tau_{\max }$, or by $1 / B$ as this limits the time lice have to approach before the fish moves on This is determined by the speed of the hosts or the limit of the time over which lice react to stimulation.

$$
X=\min \left[\lambda_{s} / B, \lambda_{s} \tau_{\max }\right]
$$

265

266

where $\tau_{\max }=1$ to 3 seconds and is the time following a stimulus over which copepodids actively move towards a host, at velocity $\lambda_{s}$ (Heuch and Karlsen 1997).

So, the lice from within a cylinder (Fig. 4) of volume $U_{w} \mathrm{~cm}^{3}$ contact the fish:

$$
U_{w}=\left(\left(\pi\left(X+r_{f}\right)^{2} \times I_{f}\right)-V_{f \tau}\right) \times B
$$

A cylinder is assumed as the simplest shape, for both the fish and its surrounding volume from which lice approach it.

Copepodid contact rate with the fish $\mathrm{s}^{-1}, \mathrm{~K}$, is the water volume in contact $\mathrm{U}_{\mathrm{w}}$ and multiplied by local copepodid concentration $C_{x}$ and probability of attachment $a$, divided by the depth of the layer the copepodids are distributed over $\mathrm{Z}$

$$
\mathrm{K}=\mathrm{aC}_{\mathrm{x}} / \mathrm{Z} \times \mathrm{U}_{\mathrm{w}}
$$

For slowly moving fish, copepodids may have longer to react and approach the host (Fig. 5).

Responses lasting for up to 3 seconds can be generated (Heuch and Karlsen 1997), so potentially copepodids could approach over a distance of $X=3 \lambda_{s}$. However if $1 / B<\tau_{\max }$ copepodid numbers become depleted before the fish moves on. For a motionless fish $\mathrm{K}=0$ because $\mathrm{B}=0$ and hence $U_{w \tau}=0$ (however, see Eq. 7). It is for this reason that fish travelling at moderate low speeds have highest rates of infestation (Samsing et al. 2015).

Once it has contacted a potential host the louse must attach to this with a probability of a. This is influenced by lice age and temperature (Skern-Mauritzen et al. 2020). In an experimental setup at $10^{\circ} \mathrm{C} 30 \%$ of copepodids attached to salmon and $50 \%$ at $14^{\circ} \mathrm{C}$, although results were highly variable (Tucker et al. 2001), as this applies under laboratory conditions it may be considered a maximum value. This indicates not all contact results in infection and default $\mathrm{a}=0.5$ is used.

\section{Lice impact on fish health and threshold concentration}

Lice induced salmonid mortality is a function of number of lice on a fish and size of that fish. This can be expressed as lice per gram infesting the individual fish, a level equivalent to $0.75 \mathrm{lice} / \mathrm{g}$ is considered to risk causing death (Grimnes and Jakobsen 1996). Taranger et al. (2015) use an estimate of $100 \%$ mortality threshold for lice loads of $>0.3$ lice $^{-1}, 50 \%$ mortality for $0.1-0.2$ lice $\mathrm{g}^{-1}$ and $0 \%$ mortality for loads of $<0.1$ lice $\mathrm{g}^{-1}$ in order to support categories of acceptability of risk of salmon aquaculture.

Given a threshold maximum infestation of $Y=0.75$ lice/g threshold (Grimnes and Jakobsen 1996) a $10 \mathrm{~g}$ smolts has a 7.5 lice per fish maximum toleration. This is equivalent to a maximum daily dose 
of $\mathrm{K}>7.5$ if exposed for one day, or $>0.75$ for fish exposed for 10 days. However lower infestation levels may be considered as the threshold limit (Taranger et al. 2015).

Critical levels of infestation are reached if infestation rate over a given time exceeds $Y=7.5$ lice per fish for these $V_{f}=10 \mathrm{~g}$ fish (or 60 lice for $80 \mathrm{~g}$ fish). For moving fish this threshold occurs if the concentration of lice $\left(C_{x} / Z\right)$ given the contact rate $K$ over a day, $D$.

So threshold concentration $C_{T}$ at which this critical level of infestation is exceeded:

$$
\mathrm{C}_{\mathrm{T}}=\left(\left(\mathrm{YV} \mathrm{V}_{\mathrm{f}} \times \mathrm{Z}\right) /(\mathrm{K} \times \mathrm{D})\right)
$$

Assuming fish density $\approx 1$ so $V_{f} \approx$ fish weight.

The equation 7 breaks down for a stationary fish, since $B=0$ implies $K=0$ and so infinite concentration of copepodids is required to reach the threshold. Copepodids within the immediate vicinity of a stationary fish, in the volume $\left(\pi\left(\tau_{\max } \lambda_{s}+r_{f}\right)^{2} \times I_{f}\right)-V_{f}$, would be able to contact that fish, so potentially a critical dose could be reached for a motionless fish. However, this would require extremely high densities of copepodids (at least 1975/a copepodids per $\mathrm{m}^{2}$ for $Z=2$ ). This situation would only affect Eq. 7 if the fish were near motionless for a day, which would mean the fish was not providing a mechanical stimulus to attract copepodids.

An alternative threshold of concern to protection of wild salmonids is the distance a fish would have to swim to reach threshold load $Y$ for a given contact rate $K$. This gives the size of patches of a given concentration that a fish can transit safely.

The attachment of lice per kilometre $\mathrm{G}$ is a function of contact rate $\mathrm{K}$ multiplied by time taken to travel distance of 1 kilometre $(100,000 \mathrm{~cm})$.

$$
\mathrm{G}=\mathrm{K} \times 100 \times 1000 /\left(\mathrm{BI}_{\mathrm{f}}\right)
$$

Recall $B \tau=1$ if $1 / B<\tau_{\max }$, so this term only applies for slow fish ( $B<1$ for $\tau_{\max }=1$ or $B<0.333$ for $\tau_{\max }$ $=3$ ).

From this a threshold distance $H_{t}$ can be derived, at which fish swimming at speed B would receive a critical dose

$$
H_{t}=Y V_{f} / G
$$

\section{Results}

Identifying a threshold concentration of lice in the water

Contact rates $\mathrm{K}$ of lice per host (derived from Eq. 6) increase with copepodid swimming speed and reaction time, but respond to fish swimming speed with a maximum at moderate swimming speed where $1 / B=\tau_{\max }$ (Fig 5). Contact rates per fish are higher for larger fish (see appendix 1 ). 


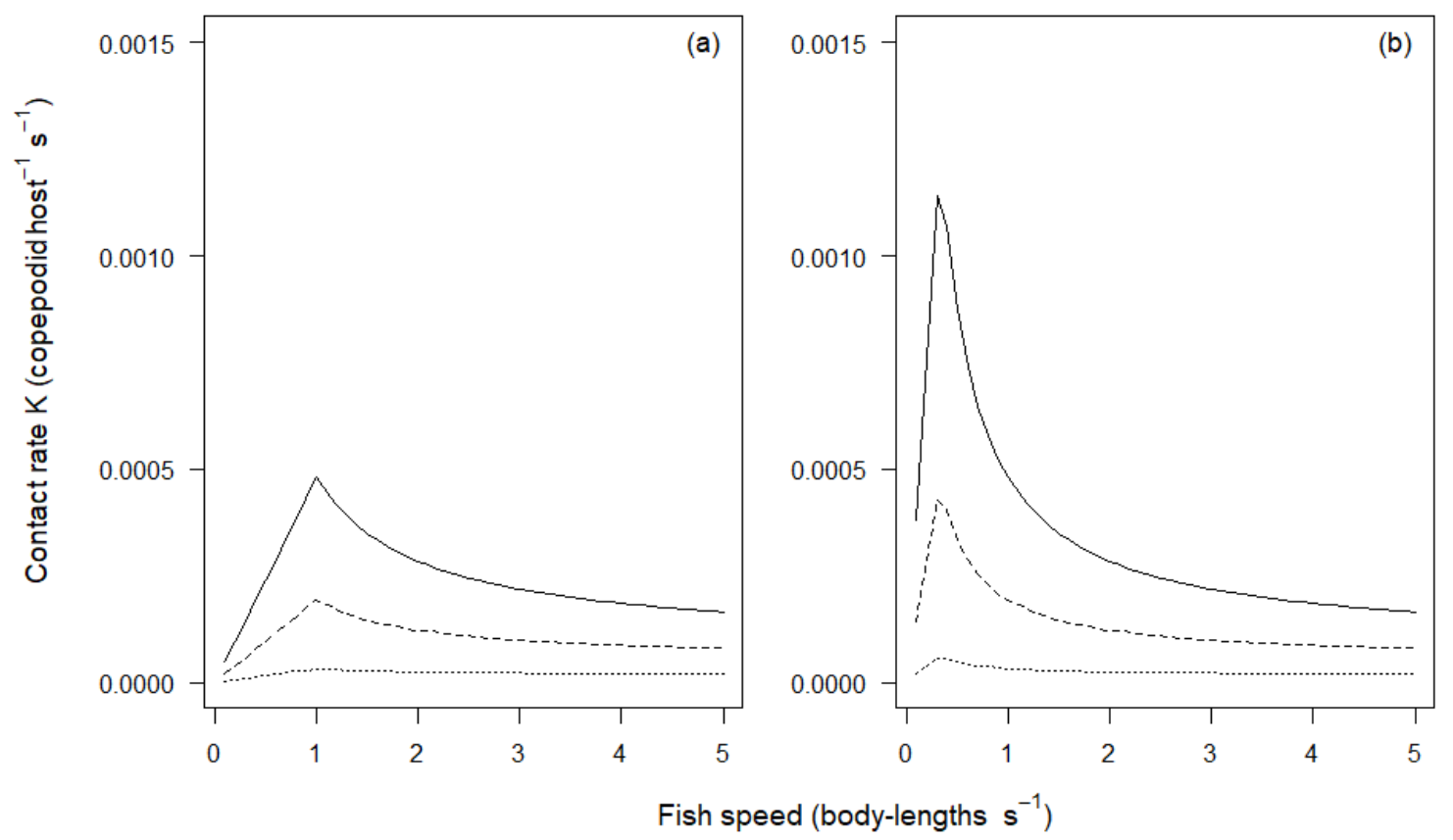

Figure 5 Contact rate $K$ (copepodids host ${ }^{-1} \mathrm{~s}^{-1}$ ) as function of $B_{s}$ for $C / Z=1$ copepodid $m^{3}$ and for copepodid velocities $\lambda_{s}$ of 1 (dot), 3 (dash) and 5 (solid) $\mathrm{cm} \mathrm{s}^{-1}$. Panels: $(5 \mathrm{a}) 10 \mathrm{~cm}$ smolts, $\tau_{\max }=1$; (5b) $10 \mathrm{~cm}$ smolts, $\tau_{\max }=3$.

Threshold levels of infestation over a day result from the contact rate (Eq. 6, Fig. 5) that would result in a critical dose of 0.75 lice $^{-1}$ of host over 24 hours (Fig. 6). Thresholds are higher for larger fish in spite of higher contact rates per fish because their larger biomass can tolerate higher lice burdens (see figures $5 x$ and $6 x$ in appendix). Thresholds also are a function of copepodid and fish swimming speeds. For copepodid velocity this is simply the faster the louse the lower the threshold. However, for fish the threshold is lowest for intermediate swimming speeds, equivalent to the inverse of copepodid reaction time $\left(1 / \tau_{\max }\right)$. Longer copepodid duration of reaction time mean lower critical thresholds, especially at intermediate and slower fish swimming speeds, but copepodid reaction time becomes irrelevant for rapidly swimming fish, because these have moved on before more distant copepodids have a chance to reach the host. 

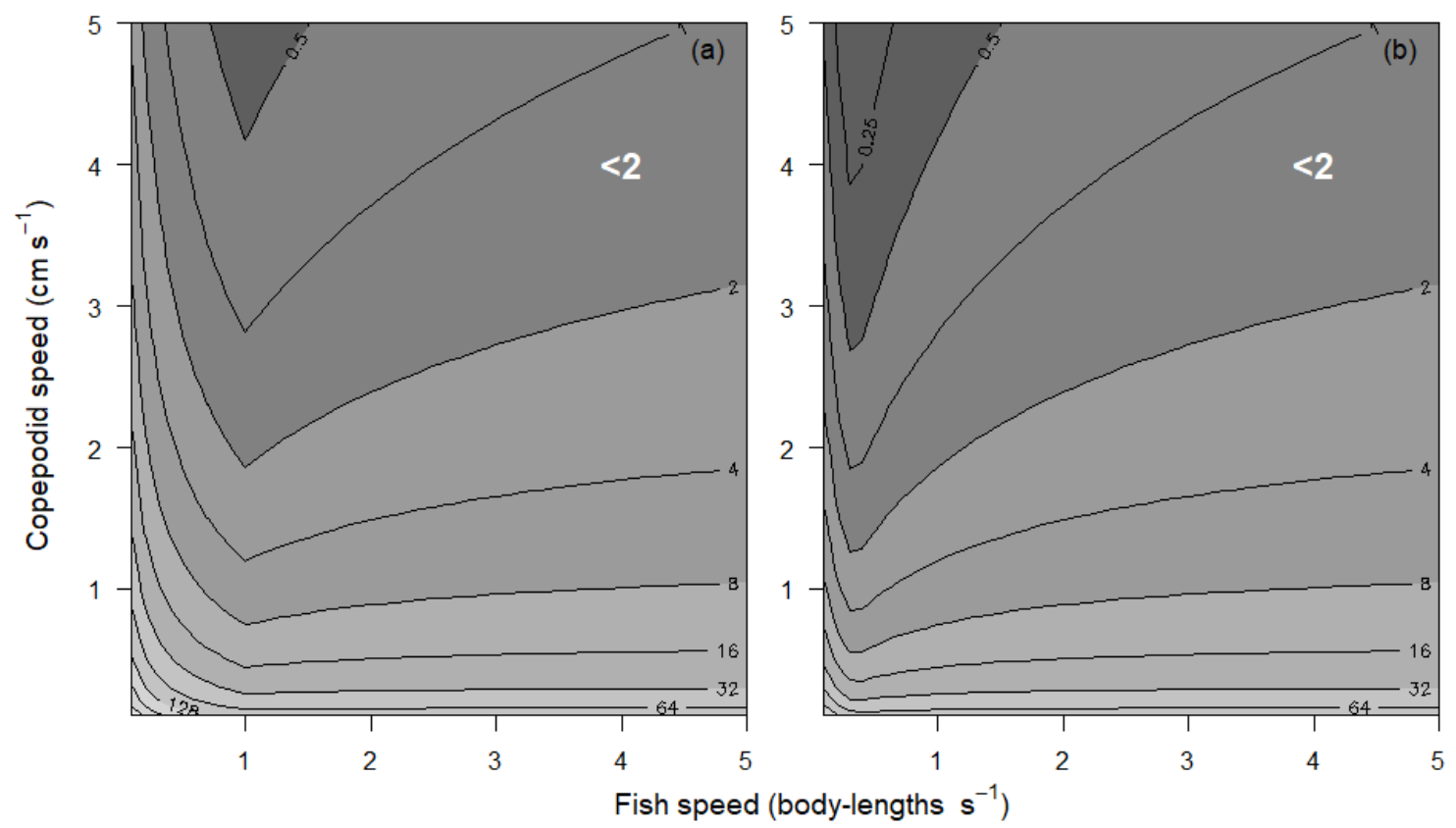

Figure 6 Copepodid concentration threshold $C_{T}$ per $\mathrm{m}^{2}$ required to reach critical dose $(0.75$ lice per gram of host) within $D=1$ day, assuming $50 \%$ attachment probability on contact ( $a=0.5), 2 \mathrm{~m}$ mixed layer $Z$ and given average lice copepodid swimming speed towards host of 0.1 to $5 \mathrm{~cm} \mathrm{~s}^{-1}$, and fish velocity of 0.1 to 5 body-lengths $s^{-1}$. Absolute value where threshold $C_{T}<2$ lice $m^{2}$ is shown on figure and covers the two darkest shades of grey. Panels: (6a) $10 \mathrm{~cm}$ smolts, $\tau_{\max }=1$; (6b) $10 \mathrm{~cm}$ smolts, $\tau_{\max }=3$.

The faster a fish swims the less time it has to pick up lice, even if the infestation rate were constant. This means they can travel greater distances before reaching a given level of infestation. As infestation rate drops for $1 / B<\tau_{\max }$ this means that faster fish have both less exposure time and lower infestation rates so beyond this point total infestation per kilometre drops particularly quickly and fish can swim for a long distance $\mathrm{H}_{\mathrm{T}}$ before they reach a critical infestation dose (Fig. 7). However, all copepodids within the reaction distance $\left(\lambda_{s} \tau_{\max }\right)$ reach fish that are swimming at $1 / B>$ $\tau_{\max }$, so the number of kilometres to reach threshold concentration does not change with fish speed lower than this. 

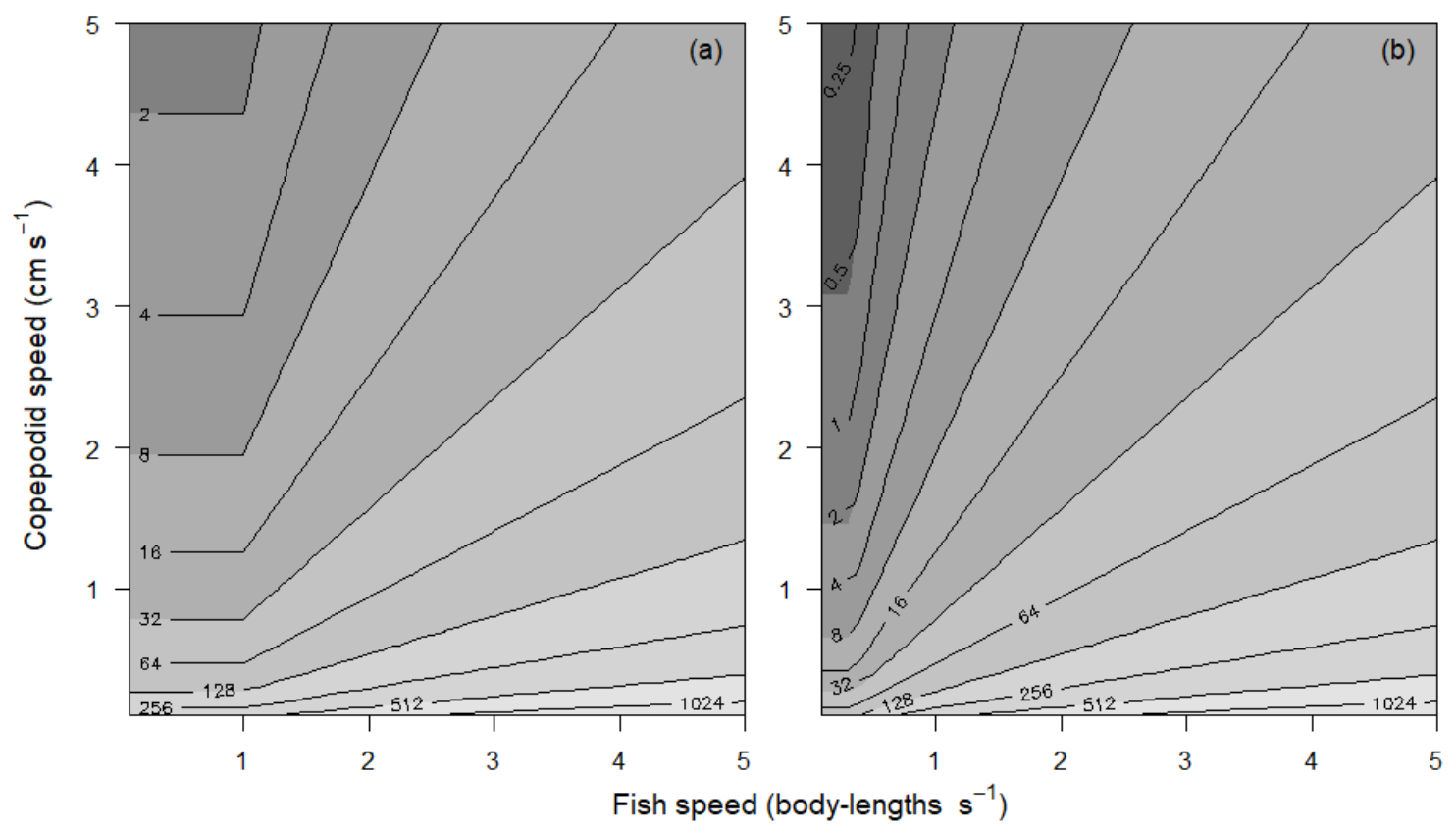

369

Figure $7 H_{T}$, distance threshold, $k m$, required for fish to swim to reach critical dose $(Y=0.75$ lice per gram of host) assuming $50 \%$ attachment probability on contact ( $a=0.5$ ), local concentration $C_{x}=2$ lice $m^{2}$ with a $2 \mathrm{~m}$ mixed layer $Z$ and given average lice copepodid swimming speed towards host of 0.1 to $5 \mathrm{~cm} \mathrm{~s}^{-1}$, and fish velocity of 0.1 to 3 body-lengths $\mathrm{s}^{-1}$. ) Panels: (7a) $10 \mathrm{~cm} \mathrm{smolts,} \tau_{\max }=1$; (7b) $10 \mathrm{~cm}$ smolts, $\tau_{\max }=3$.

Figures 5 to 7 are repeated for larger $(20 \mathrm{~cm})$ smolts in appendix 1 . While contact rates for larger fish are higher, the concentration required to reach critical dose is also higher and so is the distance over which travelling smolts can be exposed to elevated concentrations.

\section{Identifying distances at which thresholds could be exceeded}

Taking threshold concentrations of 0.2 for background long-term exposure, or 2 for acute exposure (Sandvik et al. 2020), we can use the model described above to detect areas identified as being at risk from the plume or dispersive models.

We use a 1000 tonne farm as our default, source and calculate the number of ovigerous lice per fish required to induce concentrations in excess of the thresholds at a given distance from the source farm. Results can be modified simply for different farm sizes by multiplying lice numbers on the $x$ axis by the farm biomass divided by 1000 tonnes, or plume width by dividing by the new plume width divided by $500 \mathrm{~m}$.

Given uniform dispersion the lice numbers fall rapidly with distance from the farm, and concentration in excess of 0.2 lice $\mathrm{m}^{-2}$ at $>1 \mathrm{~km}$ from the source farm only if there are more than 1 ovigerous lice per host on the farm (Fig. 8a). However, only local concentrations of $>2$ copepodids $\mathrm{m}^{-2}$ are possible near farms even at very high farm loads, if these copepodids are dispersed in all 
directions. Conversely, the plume model, assuming a $500 \mathrm{~m}$ wide plume, calculates that the concentration in the plume will exceed 2 copepodids $\mathrm{m}^{-2}$ at distances of $1 \mathrm{~km}$ from the source if lice loads exceed 0.7 ovigerous per host in a 1000 tonne farm containing 200,000 fish (Fig. 8B).
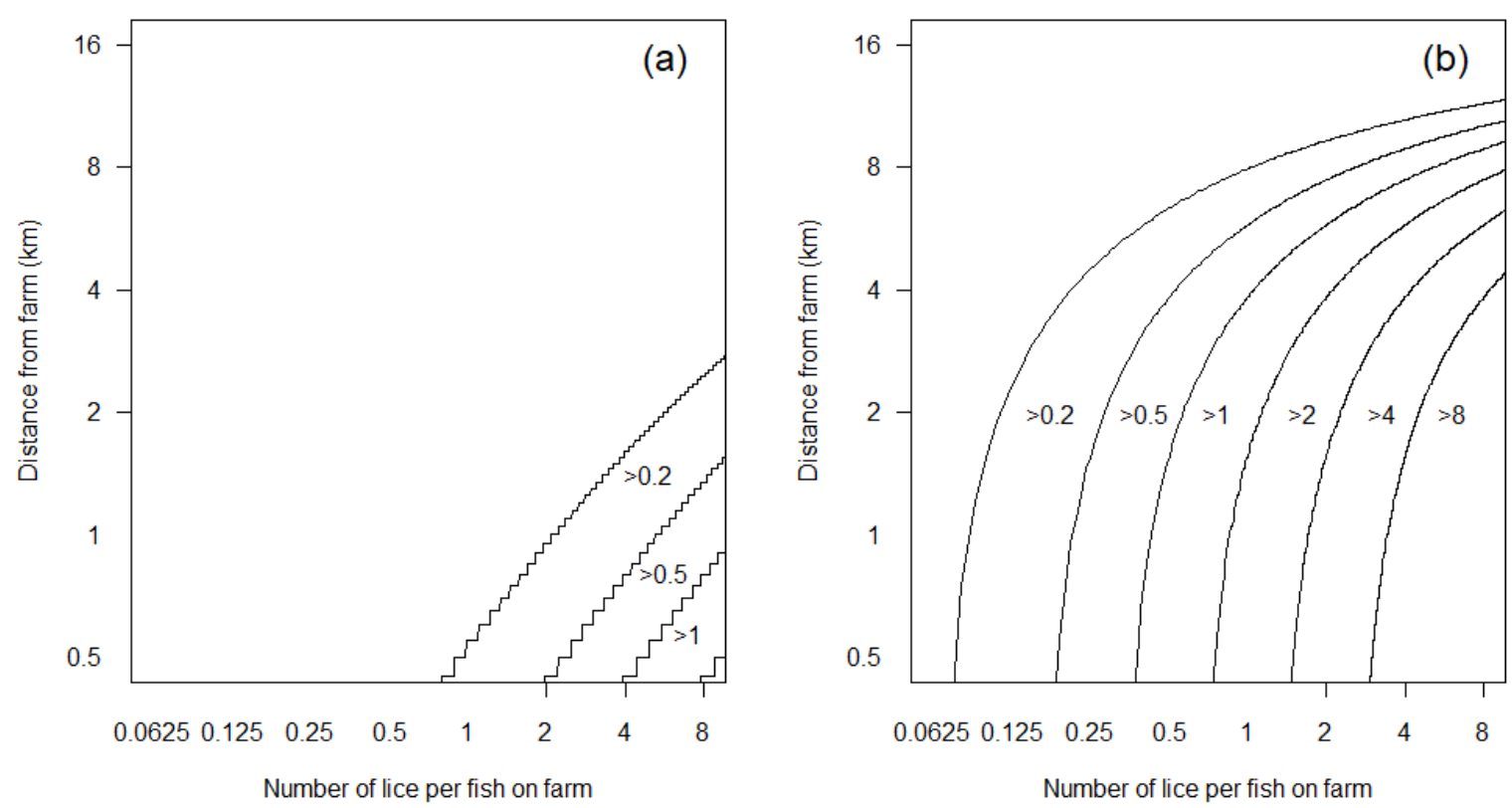

396

Figure 8 Maximum distance at which lice copepodid concentrations in the water exceed level for a given ovigerous lice loads on a 1000 tonne farm (assuming 200,000 individual fish). (a) = uniform distribution $(b)=$ plume. Contours $=0.2,-.5,1,2$ or 4 lice $\mathrm{m}^{2}(2 \mathrm{~m}$ mixed layer $)$.

\section{Discussion}

Identifying a threshold concentration of lice in the water

Modelling shows there is a fish speed at which infection is maximised (Eq. 6, Fig. 5), and therefore the threshold concentration that fish can tolerate exposure to is minimised (Eq. 7, Fig. 6). Infestation is maximised for fish moving at $1 / B=\tau_{\max }$, above this speed the faster the fish the less time lice have to react and approach the fish. Conversely, for slower fish the local lice supply is exhausted copepodids before the fish has moved on, meaning the concentration of copepodids required for a given rate of infestation is higher the slower the fish. The interaction of these effects results in greatest exposure for fish of moderately velocity (i.e. $1 / B=\tau_{\max }$, so when $B=1$ for $\tau_{\max }=1$ or $B=0.333$ for $\tau_{\max }=3$ ), and therefore these moderate to slow velocity fish have the lowest critical concentration and so have the highest potential risk.

Energy costs of swimming increase exponentially with speed and consequently the relationship between swimming speed and cost per unit distance follows a U-shaped curve with a minimum at approximately 1 body-lengths $\mathrm{s}^{-1}$ (Ware 1978). Empirical data indicate that swimming speeds of smolts are faster than this level, around 2-3 body length $\mathrm{s}^{-1}$ (Thorstad et al. 2012), but speed and time to exit coastal waters can be highly variable (Halttunen et al. 2018). Our model indicates that although such speeds may reduce energy efficiency, one benefit is that they could reduce levels of sea lice infestation, in line with the observations of Samsing et al. (2015). Hence there may be a 
trade-off between energy costs and health benefits in this context. The pattern of smolt swimming may also be important, so that fish whose average speed consists of periods of stillness interspersed with periods of high speeds may be at less risk than fish travelling a constant one body length per second (Bui et al. 2017).

The number of copepodids a fish picks up per kilometre it travels drops rapidly with increasing fish speed for $1 / B<\tau_{\max }$, because both the time of exposure and the contact rate drop. Therefore, the size of zones within which lice copepodid concentration exceeds a given level can be much larger if fish speed increases, without the fish receiving a critical load of lice. However, below this velocity $\left(1 / B>\tau_{\max }\right)$, the change in the contact rate and in the time of exposure cancel out, and so the distance travelled to reach threshold does not change with changing $B$, and therefore neither does the maximum tolerable zone size.

In summary, threshold concentrations of lice copepodids are dependent on the size and velocity of fish and the behaviour of copepodids. Smallest fish, of moderate velocity approached by rapidly moving copepodids are likely to be most susceptible to infection and most susceptible to receiving a critical dose of lice infestation. However, emigrating salmon are most likely to swim above the threshold speeds of $B<\tau_{\max }$, so contact will generally be below the theoretical maximum rate, and much lower for fish rapidly traversing the coastal zone as they migrate to oceanic feeding grounds.

\section{Identifying distances over which thresholds could be exceeded}

The kernel model allows a simple assessment of a level of ovigerous lice on farms that potentially creates a substantial local risk to native wild salmonids in the vicinity. This risk depends on the environment, and can be managed by regulating or controlling biomass and/or lice numbers on farms. In confined environments such as small fjords and sounds nauplii from farms may be most likely to mature and create infectious copepodid levels that pose a risk to wild salmonids. Infestation also occurs on farmed fish, but farm smolts are larger than wild smolts and the large populations found on farm dilutes the copepodid among many fish, therefore farmed salmon can tolerate higher copepodid concentrations than can wild salmonids. Furthermore, lice on farmed fish are treated by a range of methods (Abolofia et al. 2017). This means farmed fish are less vulnerable to infestation pressure, however farms may magnify lice infestation to generate the high infection pressure (numbers of copepodids) that can then transmit back to wild fish (Murray 2009).

Here we have used decay curve for the kernel (Fig. 2) derived from Salama et al. (2016). However, a similar decay curve, with maximum distance for detectable effect on wild sea trout is derived from observed distribution of lice on sample wild sea trout with distance from farms (Middlemas et al. 2013, Shephard et al. 2019). A decay curve that is similar, although initially steeper, is generated from the model of Aldrin et al. (2013) optimally fitted to Norwegian farm data. These patterns are of infection risk, so reflect the pattern of infection with both numbers of lice and the area over which they are dispersed. Therefore, a range of different methods generate similar decay patterns. This indicates that a kernel approach to averaged infection risk around farms is supported by multiple sources of evidence, although further work on the shape of the kernel, and more data on Scottish dispersal patterns will improve its application for risk assessment. Concentration within this kernel varies with the local environment (see next section) and so it is only intended for an averaged assessment of risk for the simple modelling here.

The kernel in figure 2 describes numbers of copepodids transported to a given distance from a farm. However the copepodid distribution is highly dependent on the nature of lice dispersal within that 
kernel, so if the lice transport is concentrated in plumes (Fig 8b) some areas distant from farms may receive substantial doses of lice (while other areas at the same distance are clear of lice), while if they disperse uniformly the copopodid concentrations drop rapidly with distance (Fig 8a). These are issues that can best be addressed by more detailed hydrodynamic modelling and will vary between farms in sheltered inshore and exposed offshore waters.

The size of areas in which lice exceeds a given concentration and the speed of the fish determines the time the fish are exposed. This risk drops rapidly as fish speed increases as both infestation rate and time of exposure decline. Since larger fish tolerate higher loads and move at higher speeds their vulnerability to receiving damaging levels of lice infestation is lower than for small fish (appendix 1).

\section{Environmental variability}

To simplify the model we use kernels describing an average concentration. In a real environment concentrations are highly variable dependent on local currents driven by local bathymetry and forcing (Amundrud and Murray 2009, Salama et al. 2018). Sea lice, owing to their vertical swimming movements, can become concentrated in down-welling currents (Murray and Salama 2018), thereby potentially forming elevated concentrations at points distant from their source. Therefore, the simple kernel modelling is intended to identify an averaged risk of infection around farms, but does not describe interaction between populations at a specific pair of locations.

We have used simple parameterisation based on rates at a standardised $10{ }^{\circ} \mathrm{C}$. However sea lice egg production and maturation is temperature sensitive (Stien et al. 2005) and this means interaction distances can vary with season (Samsing et al. 2017). Therefore consideration of seasonality, or even variation at times of changing temperature in spring and autumn may alter model results in terms of distances at which impacts potentially occur. Salinity variation in the environment is a further cause of variation in sea lice numbers and distribution as low salinity increases sea lice mortality rates (Tucker et al. 2001, Brooker et al. 2018).

The result of these variations in the environment driven by hydrography, temperature and salinity is variation in infestation risk distribution. This is a cause of uncertainty in model outputs.

\section{Model sensitivity to parameters, assessing implications for uncertainty in results}

Calculated risks of infection to a farm's neighbouring salmonid populations depend on the range of parameters included in the models outlined here. Uncertainties in parameter values can result in uncertainty in risk.

Variation in parameters may be:

(i) known variation that is well characterised;

(ii) variation whose extent is known but causes are complex or not well understood; or

(iii) variation itself is uncertain due to lack of knowledge of the system.

Type (i) variation can be used to select appropriate values for a particular scenario (e.g. maturation time for a particular temperature). For type (ii) variation a typical (usually approximating to mean) value can used, assuming variation cancels out but we cannot evaluate specific scenarios (e.g. variation in egg production). Type (iii) variation requires more data, because the typical value is 
unknown and bias may result. We may, however, be able to use other information to constrain such parameters.

The causes of variation in the different model parameters are considered in terms of the model components they describe.

(A) Nauplii production and maturation to copepodid parameters: These are here taken from existing literature, but potentially significant type (ii) uncertainties in egg production remain dependent on age of the ovigerous females and the environment their hosts live in (Brooker et al. 2018). A value for production, based on that used in other models, of 30 eggs per day per ovigerous louse, as variation is likely to even out, however eggs may hatch twice as quickly at $15^{\circ} \mathrm{c}$ than at $10{ }^{\circ} \mathrm{C}$ (Stien et al. 2005) potentially doubling production rate. Louse maturation time is sensitive to temperature, so although this pattern is fairly well constrained for a given temperature it can vary substantially dependent on temperatures (type i) and this has a potentially significant influence on survival to become infectious copepodids and on dispersal distances (Samsing et al. 2017).

(B) Copepodid dispersal pattern: Risk depends on dispersal pattern, which will vary locally. The models presented here assess potential extremes of intensity of exposure. Local distribution patterns will depend on hydrodynamics (Salama et al. 2018); which we do not attempt to reproduce here. To assess highest concentration exposure levels we assume lice are transported in a single plume, but illustrate that uniform dispersal around the kernel that would rapidly dilute lice (variants of type i variation). The kernel represents average concentration, in practice concentrations vary in both space and time within this kernel.

(C) Exposure of fish to copepodids: This is an area that introduces most uncertainty in the form of unknown variation (type iii). The two parameters required to calculate exposure are attachment on contact and copepodid swimming speed, both are uncertain. For attachment on contact we take values from literature that may overestimate risk in the environment as they were obtained in the laboratory. Swimming speed is the biggest single cause of uncertainty in the model. In particular, outlying high swim speeds have been recorded. These observations have not been included in our parameterisation of the model. Such extreme values are considered to be unlikely to occur regularly because they require very rapid and accurate reaction by all copepodids in the zone surrounding the host, and were seldom recorded. However, the fact that they were detected in laboratory experiments raises the possibility that they may be more frequent under some circumstances in the wild. However, we can also work backwards, using empirical assessment of critical concentrations of copepodids (e.g. using sentinel cages) to assess infestation rate this implies (Salama et al. 2018, Sandvik et al. 2020). Similarly, in confined experimental conditions infestation experiments have to be run over prolonged periods to obtain measurable results (e.g. 48 hours for salmon at 7.9 and 68.5 $\mathrm{kg} \mathrm{m}^{-3}$ densities, Samsing et al. 2014). Hence, infestation takes time even under conditions that would be expected to result in high encounter rates with hosts. Nevertheless, we consider that detailed assessment of swimming motion towards the host in realistic field conditions and/or better assessment of infestation rate on smolts as a function of lice copepodid concentration in the field (Sandvik et al. 2020) are required to address uncertainty in this parameter and hence the model.

(D) Impact: Here we use the value of 0.75 lice per gram of host as discussed in the text (Grimnes and Jakobsen 1996) as a set threshold for this analysis, but other threshold values may describe other physiological or behavioural responses of hosts. The implied concentrations and velocities for alternative thresholds can simply be read from Figure 6 . Risk of receiving a given dose per gram is dependent on size of hosts (type i) being highest in smallest smolts and therefore we use $10 \mathrm{~g}$ smolts for the model. 
550 Sea lice infection pressure depends on the number of ovigerous lice per fish and number of fish on 551 the farms, as well as seasonality particularly due to temperature. Ovigerous lice numbers in Scotland

552

553

554

555

556

557

558

559

560

561

562

563

564

565

566

567

568

569

570

571

572

573

574

575

576

577

578

579

580

581

582

583

584

585

586

587

588

are published as monthly averages (scottishsalmon.co.uk/reports), and shortly will move to reporting weekly averages. The numbers of fish on each farm are currently not published, clearly, publication of direct information on fish numbers would improve estimation and hence management of infection pressure. In the absence of such direct data, for a planning tool, reasonable numbers of fish later in the production cycle can be estimated from consented biomass, by dividing this biomass by the average harvestable sized fish. Highest lice numbers are found later in the production cycle (Revie et al. 2002), however, numbers of fish may be higher earlier in the production cycle owing to mortality and early harvesting. We have assumed that total lice production is highest near the point of harvest. If numbers of fish were published, this data could also be used to validate this assumption or modify the modelling of lice production.

\section{Interaction between farms and areas}

Where multiple farms are in sufficiently close proximity, the copepods produced from different farms may interact to increase the local concentrations. This means concentration threshold is more likely to be exceeded than if the farm is isolated. Interaction between plumes less likely than for uniform dispersal, because plumes occupy less space. Plumes will tend to be parallel if driven by the same current, such that only farms aligned with a prevailing current will interact. These interacting farms lead to interacting lice populations which need co-ordinated controls to manage numbers on farms (Murray and Salama 2016) and if numbers on farms are harder to control this means there will be more input into the environment (Fig. 8).

Larval lice can be transported over large distances, linking different areas of the country (Adams et al. 2016, Rabe et al. 2020). This can be important for initiation of infection for newly stocked fish or following treatment, or for gene flow, but local sources of lice are more important once infection is initiated, hence local area management is effective at constraining the bulk of lice infection (Adams et al. 2016).

Persistent unidirectional currents can lead to peak copepodid concentration (and hence infection risk) being located away from the source owing to the maturation time required for sea lice copepodids (Amundrud and Murray 2009). Sea lice can also form concentrations distant from sources as they can accumulate in downwelling currents (Murray and Salma 2018). These maturation and transport processes explain observed distributions of copepodids being more distant from source farms than are the nauplii (Penston et al. 2004).

Here we have used simplified models to generate potential lice concentrations under regimes that disperse or maintain concentrations. Their distribution of concentration may differ in reality and potentially be located away from farm sources. More detailed hydrodynamic modelling can be used to address these issues of interaction between farms (Salama et al. 2018) and areas (Adams et al. 2016).

\section{Applications to modelling exposure of sea trout}


This analysis has concentrated on interaction of sea lice with salmon smolts, however sea trout ( $S$. trutta) are also susceptible to sea lice emanating from salmon farms (Butler 2002) and a similar approach can be applied to sea trout. However sea trout have different behaviours from salmon that may affect risk from sea lice (Serra-Llinares et al. 2020). Sea trout remain in coastal water for longer periods, increasing exposure, but can return to fresh water to delouse. They may be larger when going to sea, implying higher lice loads would be required for physiological damage to occur. Therefore, although the approach described is applicable to sea trout, different parameter values will apply.

\section{Applying models to management}

The basic models outlined here provide estimates of numbers of infective lice copepodids originating from farms and free in the environment. However, the models also show the wide range of distributions of those copepodids that may result from a farm depending on the nature of spreading - from non-directional diffusions to a tight plume. Refinement of models to improve site-specific estimation of risk of exposure to lice requires local information on spatial hydrodynamics in relation to tidal cycles and weather, and also information on distributions of fish during migration, building on dispersal models (Ounsley et al. 2020). In any case, considering variation and potential bias in some parameters (see above) application of models should be part of an adaptive management process involving monitoring of actual lice levels on wild fish or free in the environment in any particular situation.

Acknowledgements: This work was funded by Marine Scotland ROAME FW0050. We thank Dr John Armstrong for suggestions that strengthened the modelling in this paper.

\section{References}

Abolofia J., Asche F., Wilen J.E. 2017 The cost of lice: quantifying the impacts of parasitic sea lice on farmed salmon. Mar Res Econ 32, 329-349

Adams TP, Aleynik D, Black KD. 2016 Temporal variability in sea lice population connectivity and implications for regional management protocols. Aquacult Env Interact 8, 585-596

Aldrin M. Storvik B, Kristoffersen AB, Jansen PA 2013 Space-time modelling of the spread of salmon lice between and within Norwegian salmon farm. PLOS One 2013, 6

Amundrud TL, Murray AG 2009 Modelling sea lice dispersion under varying environmental forcing in a Scottish sea loch. J Fish Dis 32, 27-44

Brooker AJ, Skern-Mauritzen R, Bron JE 2018 Production, mortality, and infectivity of planktonic larval sea lice, Lepeophtheirus salmonis (Kroyer, 1837): current knowledge and implications for epidemiological modelling. ICES J Mar Res 75, 1214-1234

Bui S, Oppedal F, Samsing F, Dempster T 2017 Behaviour in Atlantic salmon confers protection against an ectoparasite. J Zool 304, 73-80

Butler JRA 2002 Wild salmonids and sea louse infestations on the west coast of Scotland: sources of infection and implications for the management of marine salmon farms. Pest Man Sci 58, 595-608 
630 Cantrell DL, Rees EE, Vanderstichel R, Grant J, Filgueira R, Revie CW 2018 The use of kernel density 631 estimation with a bio-physical model provide a method to quantify connectivity among salmon 632 farms: spatial planning and management with epidemiological relevance. Frontiers Vet Sci 5, 269

633 FAO 2019. 2018 The state of world fisheries and aquaculture. Food and Agriculture Organisation of 634 the United Nations, Rome http://www.fao.org/state-of-fisheries-aquaculture/en/

635 Grimnes A \& Jakobsen PJ 1996 The physiological effects of salmon lice infection on post-smolts of 636 Atlantic salmon. J Fish Biol 48, 1179-1194

637 Halttunen E, Gjelland K- $\varnothing$, Glover KA, Johnsen IA, Serra-Llinares R-M, Skaala $\varnothing$, Nilsen R, Bjorn P-A, 638 Fiinstad B, Karsen $\varnothing$, Finstad B, Silbrei OT 2018 Migration of Atlantic salmon post-smolts in a fjord 639 with high infestation pressure of salmon lice. Mar Ecol Prog Ser 592, 243-256

640 Hamre LA, Eicher C, Caipang CMS, Dalvin ST, Dalvin ST, Bron JE, Nilsen F, Boxshall G, Skern641 Mauritzen R. 2013 The salmon louse Lepeophtheirus salmonis (Copepoda: Caligidae) life cycle has 642 only two chalimus stages. PLOS One 8, PMC3772071

643 Heuch PA, Karlsen E 1997 Detection of infrasonic water oscillations by copepodids of Lepeophtheirus 644 salmonis (Copepoda: caligidae). J Plankt Res 19, 735-747

645 Heuch PA, Mo TA 2001 A model of salmon louse production and public management measures. Dis 646 Aquat Org 45, 145-152

647 Heuch PA, Doall MH, Yen J 2007 Water flow around a fish mimic attracts a parasite and deters a 648 planktonic copepod. J Plankt Res 29, i3-i16

649 Iversen A, Asche F, Øystein H, Nyst øyl R 2020 Production costs and competitive in major salmon 650 farming countries 2003-2018. Aquaculture 2020735089

651 Jones S, Beamish R 2011 Salmon lice: an integrated approach to understanding parasite abundance 652 and distribution. Wiley-Blackwell, Chichester UK

653 Johnsen I, Harvey A, Sævik P, Sandvik A, Ugedal O, Ådlandsvik B, Wennevik V, Glover K, Karlsen $\varnothing$, 654 2020. Salmon lice induced mortality of Atlantic salmon during postsmolt migration in Norway. ICES J 655 Mar Sci doi:10.1093/icesjms/fsaa202. in press.

656 Kristoffersen AB, Jimenez D., Viljugrein H., Grontvedt R., Stien A., Jansen PA 2014 Large scale 657 modelling of salmon lice (Lepeophtheirus salmonis) infection pressure based on lice monitoring data 658 from Norwegian salmonid farms. Epidemics 9, 31-39

659 Krkošek M, Lewis MA, Volpe JP 2005 Transmission dynamics of parasitic sea lice from farm to wild 660 salmon. Proc Roy Soc B, 272 689-696

661 Malcolm IA, Millar CP, and Millidine KJ 2015 Spatio-temporal variability in Scottish smolt emigration times and sizes. Scottish Marine and Freshwater Science Vol.6 No.2

663 https://www2.gov.scot/Resource/0047/00472202.pdf

664 Mancilla-Schulz J, Marin SL, Molinet C 2019 Dynamics of Caligus rogercressyi (Boxshall \& Bravo, 665 2000) in farmed Atlantic salmon (Salmo salar) in southern Chile: Are we controlling sea lice? J Fish 666 Dis 42, 357-369

667 Middlemas SJ, Fryer RJ, Tulett D, Armstrong JD 2013 Relationship between sea lice levels on sea 668 trout and farm fish activity in western Scotland. Fisher Manag Ecol 20, 68-74 
669 Mordue (Luntz) AJ, Birkett MA 2009 A review of host finding behaviour in the parasitic sea louse, 670 Lepeophtheirus salmonis (Caligidae: Copepoda). J Fish Dis 32, 3-13

671 Murray AG 2009 Using simple models to review the application and implications of different 672 approaches used to simulate transmission of pathogens among aquatic animals. Prev Vet Med 88, $673 \quad 167-177$

674 Murray AG, Gubbins M 2016 Spatial management measures for disease mitigation as practiced in 675 Scottish aquaculture. Mar Pol 70, 93-100

676 Murray AG, Salama NKG 2016 A simple model of the role of area management in the control of sea 677 lice. Ecol Modell 337, 39-47

678 Murray AG, Salama NKG 2018 Modelling disease in aquatic systems that are spread by processes 679 operating at different temporal and spatial scale: examples from salmon aquaculture. CAB Reviews $680 \quad 12,32 \mathrm{p} 1-11$

681 Ounsley JP, Gallego A, Morris DJ, Armstrong JD 2020 Regional variation in directed swimming by 682 Atlantic salmon smolts leaving Scottish waters for their oceanic feeding grounds - a modelling study. 683 ICES J Mari Sci 77, 315-325

684 Penston MJ, McKibben MA, Hay DW, Gillibrand PA 2004. Observations on open-water densities of 685 sea lice larvae in Loch Sheidaig, western Scotland. Aquacult Res 35, 793-805

686 Pradeepkiran JA 2019 Aquaculture role in global food security with nutritional value: a review. 687 Translational Animal Sci 3, 903-910

688 Rabe B., Gallego A., Wolf J., O'Hara Murray R, Stuiver C., Price D., Johnson H. 2020 Applied 689 connectivity modelling at local to regional scale: the potential for sea lice transmission between 690 Scottish finfish aquaculture management areas. Est, Coast Shelf Sci 238, 106716

691 Revie CW, Gettinby G, Treasurer JW, Rae GH, Clark N 2002. Temporal, environmental, and 692 management factors influencing the epidemiological patterns of sea lice (Lepeophtheirus salmonis) 693 infestations on farmed Atlantic salmon (Salmo salar) in Scotland. Pest Managt Sci 58,576-584

694 Salama NKG, Murray AG, Rabe B 2016 Simulated environmental transport distances of 695 Lepeophtheirus salmonis in Loch Linnhe, Scotland, for informing aquaculture area management 696 structures. J Fish Dis 39, 419-428

697 Salama NKG, Dale AC, Ivanov VV, Cook PF, Pert CC, Collins CM, Rabe B 2018 Using biological-physical 698 modelling for informing sea lice dispersal in Loch Linnhe, Scotland. J Fish Dis 41, 901-919

699 Samsing F, Oppedal F, Johansson D, Bui S, Dempster T 2014 High host densities dilute sea lice 700 Lepeophtheirus salmonis loads on individual salmon, but do not reduce lice infection success. 701 Aquacult Env Int 6, 81-89

702 Samsing F, Solstrom D, Oppedal F, Sostrom F, Dempster T 2015 Gone with the flow: current 703 velocities mediate parasitic infestation of an aquatic hosts. Int J Parasitol. 45, 559-565

704 Samsing F, Johnsen I, Dempster T, Oppedal F, Treml EA 2017 Network analysis reveals strong 705 seasonality in the dispersal patterns of a marine parasite and identifies areas for coordinated 706 management. Landscape Ecol 32, 1953-1967 
Sandvik AD, Johnsen IA, Myksvoll MS, Sævik PN, Skogen MD 2020 Prediction of the salmon lice infestation pressure in a Norwegian fjord. ICES J Mar Sci 77, 746-756

Serra-Llinares RM, B $\emptyset \mathrm{hn} T$, Karlsen $\varnothing$, Nilsen R and others (2020) Impacts of salmon lice on mortality, marine migration distance and premature return in sea trout. Mar Ecol Prog Ser 635:151-168.

Shephard S, Maclntyre C, Gargan P 2019 Aquaculture and environmental drivers of salmon lice infestation and body condition in sea trout. Aquacult Env Int 8, 597-610

Stien A, Bjorn PA, Elston DA 2005 Population dynamics of salmon lice Lepeophtheirus salmonis on Atlantic salmon and sea trout. Mar Ecol Prog Ser 290, 263-275

Skarđhamar J. Albretsen J., Sandvik A.D., Lien, V.S., Myksvoll M.S., Johnsen I.A., Asplin L., Ådlandsvik B., Halttunen E., Bjørn P.A. 2018 Modelling salmon lice dispersion and infestation patterns in a subarctic fjord. ICES J Mar Sci 75, 1733-1747

Skern-Mauritzen R, Sissener NH, Sandvik AD, Meier S, Sævik PN, Skogen MD, Vågseth T, Dalvin S, Skern-Mauritzen M, Bui S 2020 Parasite development affect dispersal dynamics; infectivity, activity and energetic status in cohorts of salmon louse copepodids. J Exp Mar Biol Ecol 530-531, 151429

Taranger GL, Karlsen $\varnothing$, Bannister RJ, Glover KA, Husa V., Larlsbakk E., Kvamme B.O.,Boxaspen K.K., Bjørn PA, Finstad B., Madhun A.S., Morton H.C., Svasand T. 2015 Risk assessment of the environmental impact of Norwegian Atlantic salmon farming. ICES J Mar Sci 72, 997-1021

Thorstad EB, Whoriskey F, Uglem I, Moore A, Rikardsen AH, Finstad B 2012 A critical life stage of the Atlantic salmon Salmo salar: behaviour and survival during the smolt and initial post-smolt migration. Fish Biol 81, 500-542

Tucker CS, Sommerille C, Wooten R 2001. The effect of temperature and salinity on the settlement and survival of copepodids of Lepeophtheirus salmonis (Krøyer, 1837) on Atlantic salmon, Salmo salar L. J Fish Dis 23, 309-320

Vollset KW, Krontveit RI, Jansen PA, Finstad B, Barlup BT, Skilbrei OT, Krkosek M, Romstad P, Jensen AJ, Dohoo I. 2016 Impact of parasites on marine survival of Atlantic salmon: a meta-analysis. Fish Fisher 17, 714-730

Ware DM 1978. Bioenergetics of pelagic fish: Theoretical change in swimming speed and ration with body size. J Fish Res Bd Can 35, 220-228

Ziegler F., Winther U., Hognes E.S., Emanuelsson A., Sund V., Elingsen H. 2013 The carbon footprint of Norwegian seafood products on the global seafood market. J Industrial Ecol 17, 103-116 
739

The contact rate graphs for lice, 5, 6 and 7 in the main text illustrate the effects on infestation of smolt and copepodid movement behaviours for small $10 \mathrm{~cm}$ smolts. These small fish are the most likely to receive infestation levels that are above threshold maximum lice per gram, $\mathrm{Y}$, and therefore most important in determining maximum copepodid concentration exposure limits.

However, for this same reason that the effect of smolt size does have an impact on their susceptibility, it is useful to illustrate the exposure risks of larger smolts. Therefore we include variants of figures 5, 6 and 7 calculated for $20 \mathrm{~cm}(80 \mathrm{~g})$ smolts, as opposed to the $10 \mathrm{~cm}$ smolts used to illustrate results in the main text. The graphs are labelled $5 x, 6 x$ and $7 x$, for comparison with the appropriate graphs in the main text, and the panels are labelled as $c$ and $d$ as they follow on from panels $a$ and $b$ in figures in the main text.

The effect of larger $20 \mathrm{~cm}$ smolts is a higher contact rates per fish (fig. 5x versus fig. 5), but only relatively slow moving larger smolts are likely to receive a critical does of lice (fig. 6x versus fig. 6) and larger smolts are able to cope with transiting through much larger distances with high concentrations of copepodid lice (fig. $7 x$ versus fig.7).

Therefore, wild smolt size is an important factor in their vulnerability to copepodid concentrations and hence to permissible numbers of adult lice on salmon farms.

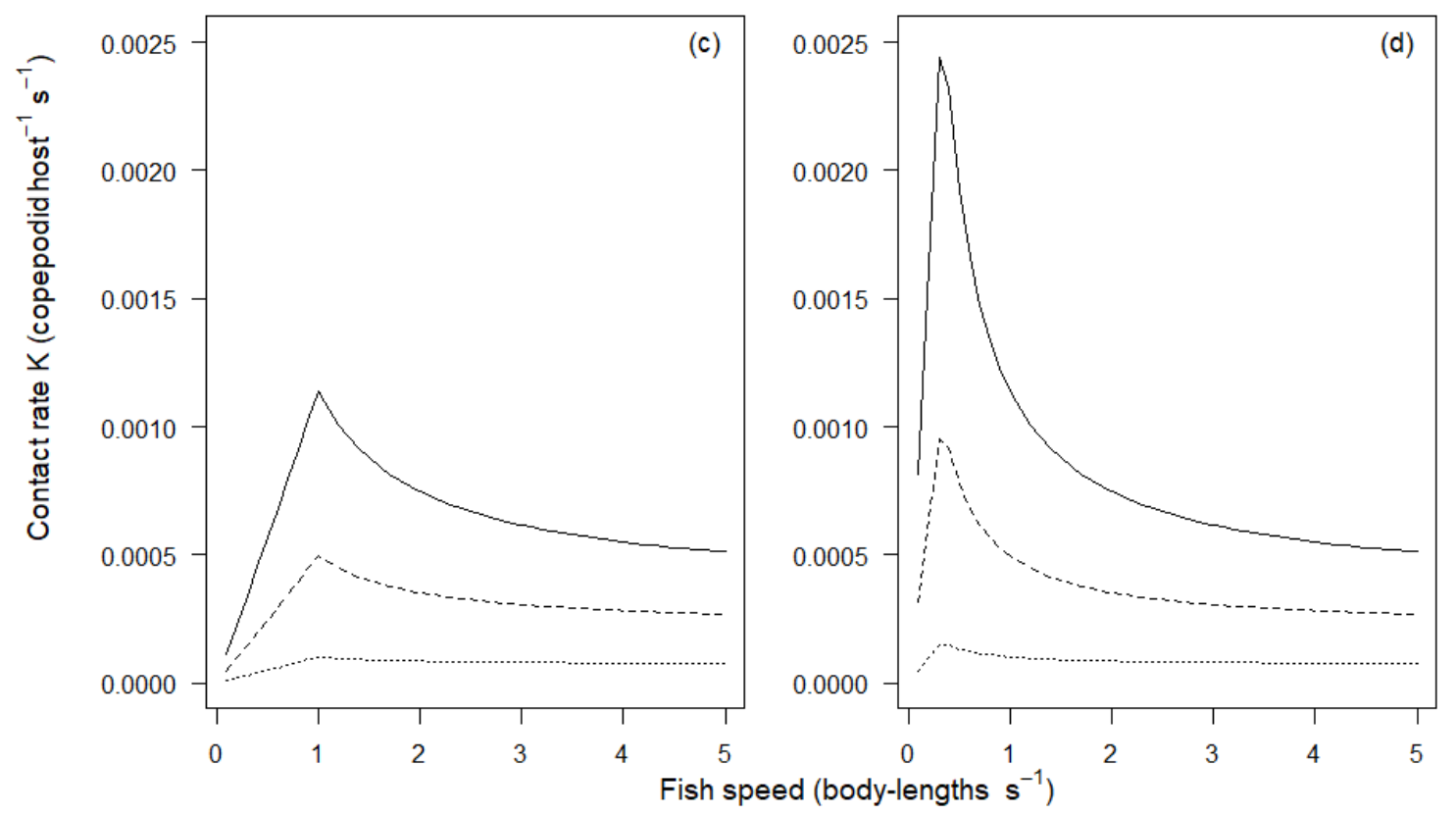

755

Figure $5 x$ Contact rate $K$ (copepodids host ${ }^{-1} s^{-1}$ ) as function of $B_{s}$ for $C / Z=1$ copepodid $m^{3}$ and for copepodid velocities $\lambda_{s}$ of 1 (dot), 3 (dash) and 5 (solid) $\mathrm{cm} \mathrm{s}^{-1}$. Panels: $(5 x \mathrm{c}) 20 \mathrm{~cm}$ smolts $\tau_{\max }=1$; (5xd) $20 \mathrm{~cm}$ smolts $\tau_{\max }=3$. (note different $y$-axis scale to fig 5 in text) 

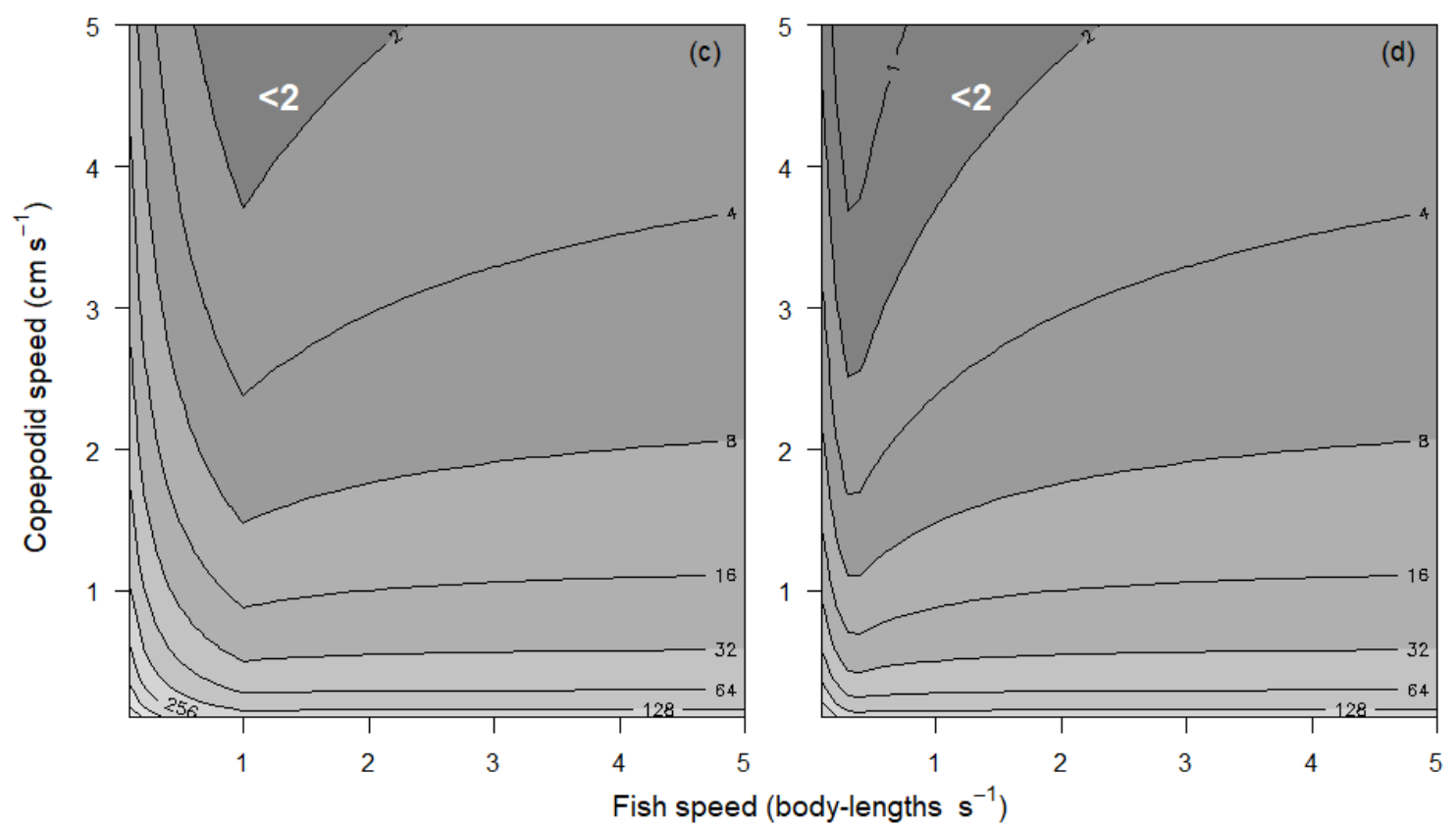

Fish speed (body-lengths $s^{-1}$ )

761 Figure $6 x$ Copepodid concentration threshold $C_{T}$ per $\mathrm{m}^{2}$ required to reach critical dose $(0.75$ lice per gram of host) within $D=1$ day, assuming $50 \%$ attachment probability on contact ( $a=0.5), 2 \mathrm{~m}$ mixed layer $Z$ and given average lice copepodid swimming speed towards host of 0.1 to $5 \mathrm{~cm} \mathrm{~s}^{-1}$, and fish velocity of 0.1 to 5 body-lengths $\mathrm{s}^{-1}$. Absolute value where threshold $<2$ lice $m^{2}$ is shown on figure and covers darkest shade of grey (note even darker shade in fig 6 in main text does not apply to this figure because the larger fish here in fig $6 x$ are not vulnerable to the very lowest copepodid concentrations for the conditions given). Panels: $(6 x c) 20 \mathrm{~cm}$ smolts, $\tau_{\max }=1$; $(6 x d) 20 \mathrm{~cm}$ smolts, $\tau_{\max }=3$. 

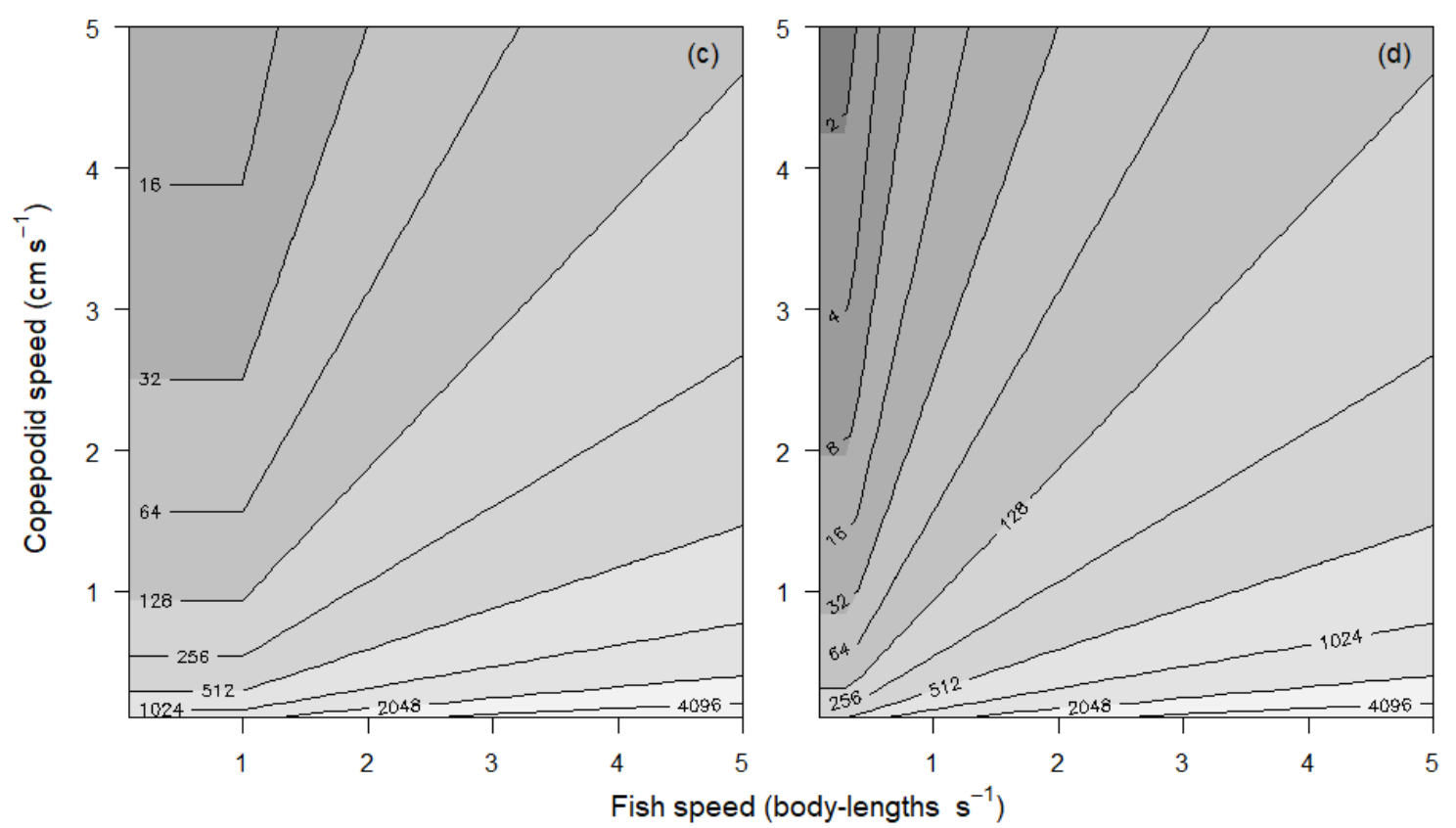

Fish speed (body-lengths $\mathrm{s}^{-1}$ )

771 Figure $7 \times \mathrm{H}_{t}$ distance threshold, $\mathrm{km}$, required for fish to swim to reach critical dose (0.75 lice per 772 gram of host) assuming 50\% attachment probability on contact $(a=0.5)$, local concentration $C_{x}=2$ 773 lice $m^{2}$ with a $2 \mathrm{~m}$ mixed layer $Z$ and given average lice copepodid swimming speed towards host of 7740.1 to $5 \mathrm{~cm} \mathrm{~s}^{-1}$, and fish velocity of 0.1 to 3 body-lengths $\mathrm{s}^{-1}$. ) Panels: (6xc) $20 \mathrm{~cm}$ smolts, $\tau_{\max }=1$; $775(6 x d) 20 \mathrm{~cm}$ smolts, $\tau_{\max }=3$. 